\title{
The mutual relationship between the monitoring and modelling of estuarine ecosystems*
}

\author{
V. N. de Jonge ${ }^{1} \&$ E. G. DeGroodt ${ }^{2}$ \\ ${ }^{1}$ Rijkswaterstaat, Tidal Waters Division; P.O. Box 207, 9750 AE Haren, \\ The Netherlands \\ ${ }^{2}$ Delft Hydraulics; P.O. Box 177, $2600 \mathrm{MH}$ Delft, The Netherlands
}

\begin{abstract}
A general simulation model developed for the Ems estuary (a part of the Wadden Sea), to describe the main carbon flow through the foodweb, was applied for monitoring purposes. In this model, the estuary is divided into five compartments, in each of which a pelagic, an epibenthic and a benthic submodel operates. A transport model regulates the distribution of dissolved and particulate substances over the area. Two parameters that partly regulate the carbon flow are the concentrations of phosphate and of the particles (turbidity) in the water. From the sensitivity analyses for phosphate and turbidity it can be concluded that the relative effects of changes in turbidity and changes in the influx of phosphate from the rivers are large in the upper reaches and small in the lowest reaches of the estuary. This is due to the increasing influence of the coastal waters in the lower reaches. These results indicate that the reaches, which represent the beginning and the end of a gradient in the estuary, are also very suitable for monitoring the quality status of this estuary in terms of production and standing stock of groups of organisms. The need to use monitored data from the boundaries (sea and rivers) of those ecosystems as input in simulation models is discussed. Moreover, the possibilities of using simulation models to generate new ideas on the functioning of estuarine ecosystems under changing environmental conditions and to help administrators to decide on specific future management strategies are also discussed.
\end{abstract}

\section{INTRODUCTION}

Estuaries like that of the Ems are very dynamic areas. These dynamics are caused primarily by the physics, the interactions between tides and river discharges in a system that consists in equal proportions of tidal flats and gullies (de Jonge, 1988). This results in a strongly fluctuating longitudinal dispersion of estuarine water and its dissolved and fine particulate substances. In the Ems estuary, this dispersion is only partly a function of river discharge (Dorrestein \& Otto, 1960; Helder \& Ruardij, 1982; but a recent study carried out by de Jonge showed it to be mainly caused by residual currents). Dissolved and particulate substances are transported to the estuaries together with the fresh water. Particulate matter is also imported from the sea (Postma, 1967) while dissolved substances from the sea are brought into the estuary by water exchange.

At least three external factors govern the functioning of these complex systems. The first factor is the influence of the rivers. Today, the rivers carry huge amounts of nutrients,

\footnotetext{
- Presented at the VI International Wadden Sea Symposium (Biologische Anstalt Helgoland, Wattenmeerstation Sylt, D-2282 List, FRG, 1-4 November 1988)
} 


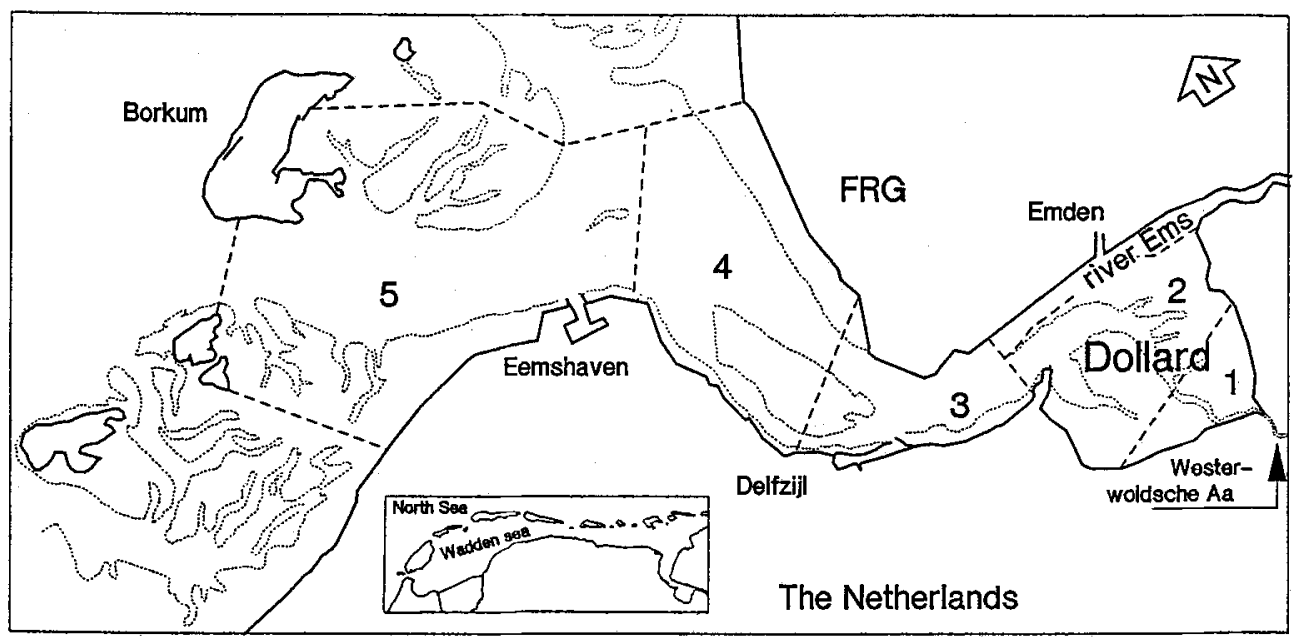

Fig. 1. Map of the Ems estuary showing the 5 model compartments (dashed lines). The dotted lines (mean low water level) indicate the boundaries between channels and tidal flats

organic matter, and contaminants such as heavy metals and chlorinated hydrocarbons to the estuaries. Depending on the flushing time and reactivity of the different compounds, riverborne substances can have various effects, first of all within the river system itself, but also in the estuary. For example, the estuary of the River Ems (Fig. 1) receives per annum approximately 25000 tons of nitrogen, 3000 tons of phosphorus and 40000 tons of organic carbon from the Ems and Westerwoldsche Aa rivers (de Jonge, 1988). These discharges give rise to a concentration gradient in nutrients e.g. phosphate, which is steeper today (de Jonge \& Villerius, 1989) than the gradients measured in the past (Postma, 1960; de Jonge \& Postma, 1974): when nutrient loads increase, this will be followed by an increase in the annual primary production (de Jonge, 1989). Which nutrient (nitrogen or phosphorus) is the key factor for algal growth is dependent on, for example, the N/P ratio.

The second external factor that governs the functioning of estuarine systems is the influence of the sea. Estuaries are usually accumulation areas for sediment and associated organic matter. This material is mainiy of marine origin (Postma, 1967). Very recently it was indicated that the North Sea can be a significant source of calcite which mineral is thought to regulate in part the estuarine phosphorus cycle (de Jonge \& Villerius, 1989). Changes in both the concentrations of calcite or phosphorus could affect this cycle quantitatively although this quantification is not yet possible. Thus, the sea is an important contributor of particulate matter and, also, of organic matter, nutrients and contaminants. This means that the quality status of the North Sea coastal zone undoubtedly plays a role in the quality status of Dutch estuaries (cf. DeGroodt \& de Jonge, 1989) and thus can also play a role in the disturbance of the functioning of those ecosystems.

The third factor is the anthropogenic disturbance of the system. A good example is the effect of dredging and sand extraction in the estuary of the River Ems (de Jonge, 1983). The following effects have been identified: changed tidal amplitudes, changed tidal prisms and consequently a changed erosion and sedimentation cycle resulting in 
changed suspended matter concentrations and hence in changed turbidity. The changes in mean annual concentrations of suspended matter in the Ems estuary are correlated with the length dredged annually and not with the volumes dredged or dumped (de Jonge, 1983). Thus, a complete chain of changes can be instigated by a single type of disturbance.

These examples illustrate that external sources, such as (river) discharges, and internal factors, such as anthropogenic activities, can be responsible for changes in the natural estuarine processes, such as primary production and possibly also secondary production and conditions, such as concentrations of suspended matter (turbidity), and can thus be responsible for changes in the functioning of the organisms there, whose activity is determined by growth-stimulating factors as well as by stress factors. The question is not only how substances are distributed under different physical conditions, but, more important, how marine plants and animals react in the short- and the long-term to the substances once these have been distributed.

An important question is, therefore, where the sampling plots for a monitoring programme should be located in such a system, so that changes in processes or species composition can be documented. To find an answer, several sensitivity runs were carried out by the authors (cf. also DeGroodt \& de Jonge, 1989) with a computer simulation model of the ecosystem of the Ems estuary which was published earlier (Baretta \& Ruardij, 1988). From these results it will be shown that this type of model can be used to justify the choice of sampling areas for monitoring. The necessity of using monitoring data as input into ecosystem models to verify or falsify these models will also be discussed in this paper.

\section{METHODS}

\section{Structure of the simulation model}

The ecosystem model of the Ems estuary consists of four submodels (Fig. 2). Because of the existing gradients in nearly all parameters, the Ems estuary was divided into five compartments (Fig. 1), in each of which the biological system is simulated by three submodels (pelagic, benthic and epibenthic). All transports of water, nutrients, dissolved and particulate carbon, including pelagic organisms, are incorporated in a fourth submodel, a transport model, which connects all other submodels with each other by the water column. The model has been calibrated with data obtained mainly in 1978 . This calibrated model is called the standard model (Baretta \& Ruardij, 1988).

The organisms in the model were combined in functional groups, which comprise species with a similar life-style. The model is a carbon flux model, which implies that biomass is expressed as grams carbon per unit of area or per unit of volume. The activity of groups of organisms is expressed as carbon fluxes per unit of time per unit of area (or volume).

\section{Analysis}

Sensitivity analyses were carried out for phosphate and turbidity, both relevant growth parameters for algae. Nitrogen was not modelled because phosphorus is potentially the nutrient that limits algal growth in Dutch coastal waters (de Jonge, 1989). Not the total phosphorus cycle but only the discharge of dissolved inorganic phosphate was 


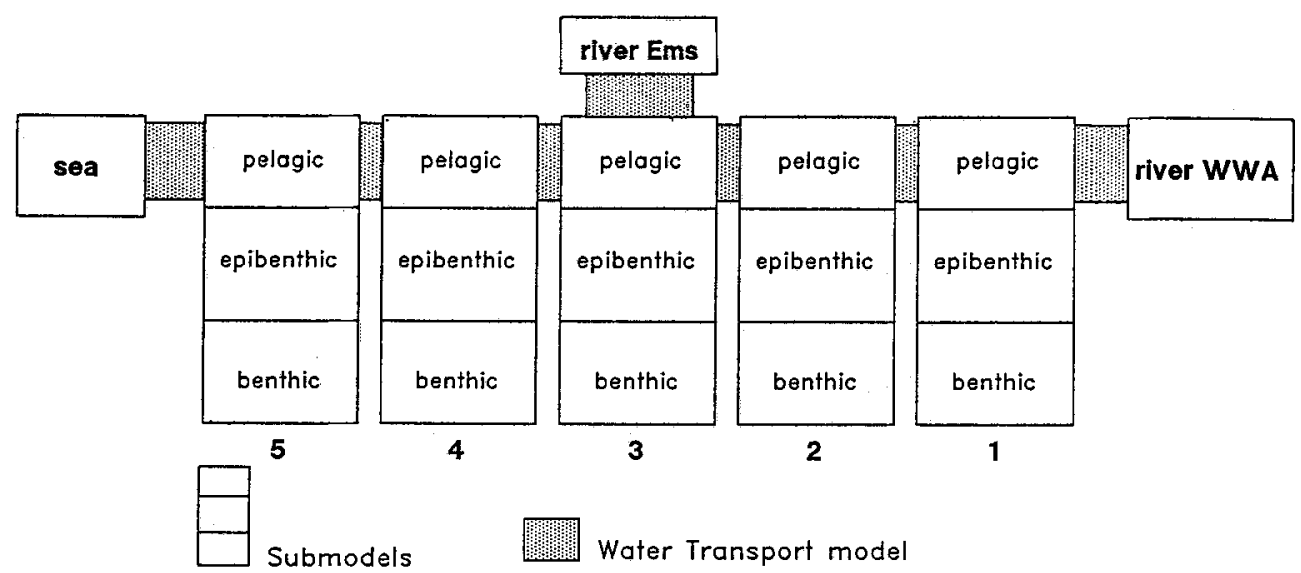

Fig. 2. Diagrammatic representation of the set-up of the ecosystem model of the estuary

modelled because the supply of this nutrient fraction can be indicated to be the key factor for algal growth (de Jonge, 1989). The phosphate loads of the River Ems and the River Westerwoldsche Aa were doubled $(200 \%)$ or halved $(50 \%)$. The phosphate concentrations at the sea boundary were maintained at the level of the standard model because we found that when only the transport of phosphate is considered (i.e. changes caused by biotics are ignored), the phosphate concentrations at the sea boundary appear to be less than $4 \%$ of the values present in the standard model. Therefore, we concluded that it was not necessary to change the phosphate concentrations at the sea boundary simultaneously with a change in the phosphate loads of the rivers (cf. DeGroodt \& de Jonge, 1989).

To mimic changes in turbidity, due to increase of suspended matter, the light extinction for all compartments was changed in the model. Furthermore, the efficiency of the food selection of filter feeders was decreased when the turbidity (suspended matter concentration) doubled and it was increased when the turbidity was halved. This was done because the concentration of suspended particles influences the energy balance of the filter-feeders (Widdows et al., 1979). They are unable to select the useful particles before filtering the water. Thus selection after particle intake is required. Useless particles are excreted as faecal pellets and this process requires a lot of energy.

Due to dredging, the utilisable fraction in the suspended matter will decrease, as mainly useless material is resuspended. Because of the structure of the model in which the transport of suspended matter plays a significant role, it was not possible to simply change the concentration of the suspended matter. It was, however, very easy to change the light extinction and the food selection in the model. This manipulation gives exactly the same results as a change in the suspended matter concentrations.

Halving the turbidity (de Jonge, 1983) and halving the phosphate concentrations (Postma, 1960) produces a situation resembling that prevailing in the mid-1950s. For this period, only some summer (July) values were published for phosphate (Postma, 1960) ranging from $0.8 \mu \mathrm{M}$ in the lower reaches to $2 \mu \mathrm{M}$ in the turbidity maximum. These values are substantially lower than the values measured today, where, in the turbidity zone in which heterotrophic processes dominate, phosphate values are measured varying between 5 and $6 \mu \mathrm{M}$. The annual mean suspended matter concentration for the total 
estuary for the early fifties was calculated from data of Postma (1960) and published by de Jonge (1983) to be a value of approx. $45 \mathrm{mg} \cdot \mathrm{l}^{-1}$. This is clearly lower than the values from the mid seventies $\left(60 \mathrm{mg} \cdot \mathrm{1}^{-1}\right)$ with which the present model was calibrated. Doubling the turbidity mimics the situation prevailing in the late 1970 s due to extensive dredging operations (de Jonge, 1983), whereas the doubling of the phosphate levels represents a new situation.

The overall results of the sensitivity analyses are given as changes in annual mean biomass relative to the biomass of the standard run in which all the values were considered to be $100 \%$.

\section{RESULTS AND DISCUSSION}

As an example, in Figure 3 the annual simulation runs for three compartments $(1,3$ and 5) are presented for the biomass of the phytoplanktonic diatoms and the phytoplanktonic flagellates, two groups that strongly respond to changes in turbidity and in phosphate supply. Shown are the runs of the standard model and the $50 \%$ runs for both phosphate and turbidity. For the actual field data of the standard model, the reader is referred to Baretta \& Ruardij (1988). The curves illustrate clearly the reaction of the two algal groups. Especially the diatoms in compartment 1 react strongly to changes in light because of a high phosphate supply to an area where algal growth is light-limited in the standard model. The strong reaction to phosphate in compartment 1 and not in 5 has to do with the high North Sea phosphate supply to compartment 5 during spring. This supply is caused by high water exchange (Fig. 4). This strong water exchange in compartment 5 mainly compensates for the decreased river supply. The overall reaction of the flagellates to the improvement of light conditions is relatively low and mainly caused by the decreased phosphate concentrations in the coastal area in summer (cf. Fig. 4). Also the flagellates react strongest in compartment 1 to both a reduction of phosphate supply and to a reduction of turbidity.

The overall results of the sensitivity runs are given in Figure 5 and 6 as annual mean biomass values. They are restricted to those groups of organisms that showed significant changes in their mean annual standing stocks over the year. These groups are the planktonic diatoms, the phytoplankton that use no silicate (flagellates), the planktonic copepods, the micro-zooplankton and the benthic suspension feeders. Figure 5 shows that under conditions of decreasing as well as of increasing phosphate discharge (eutrophication), the biota in the innermost compartment react strongest of all, with the exception of the benthic suspension feeders. This group is nearly absent in that compartment because of frequent anoxic conditions during the autumn and winter. The biota in compartment 5 near the sea react minimally or not at all. This is (see also above) because of the strong exchange of water and, consequently, the strong phosphate fluxes between the sea and this compartment number 5 (DeGroodt \& de Jonge, 1989). In fact, the sea is an infinite source of nutrients in the model. The results of the simulations show that the effects of varying phosphate and turbidity can be approximately linearly interpolated between compartments 1 and 5, excepting the suspension feeders which are, as stated above, nearly absent in compartment 1 due to anoxic conditions. In general, it can be concluded that for monitoring the effects of changes in nutrient supply on the primary and secondary production or the biomass values of specific groups of organisms, sampling can be restricted to the upper and the lower reaches of the estuary. When the 

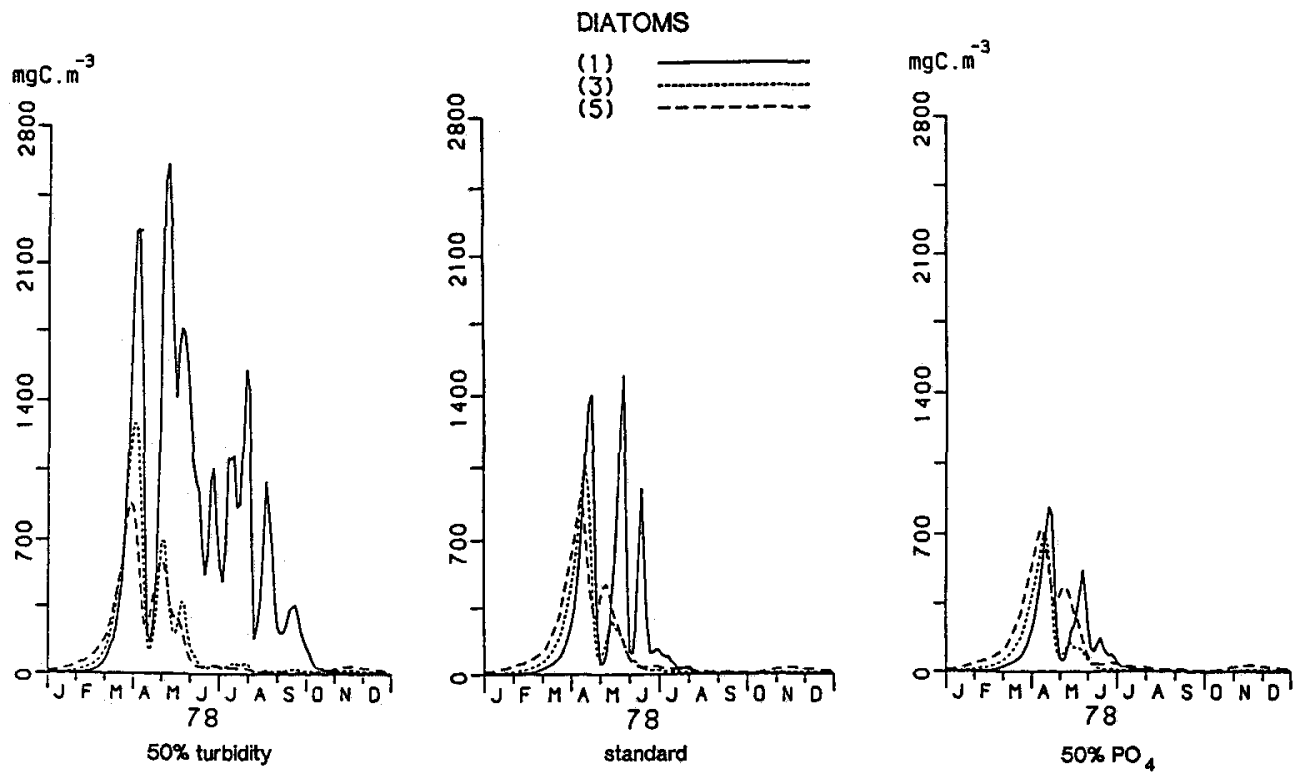

\section{FLAGELLATES}
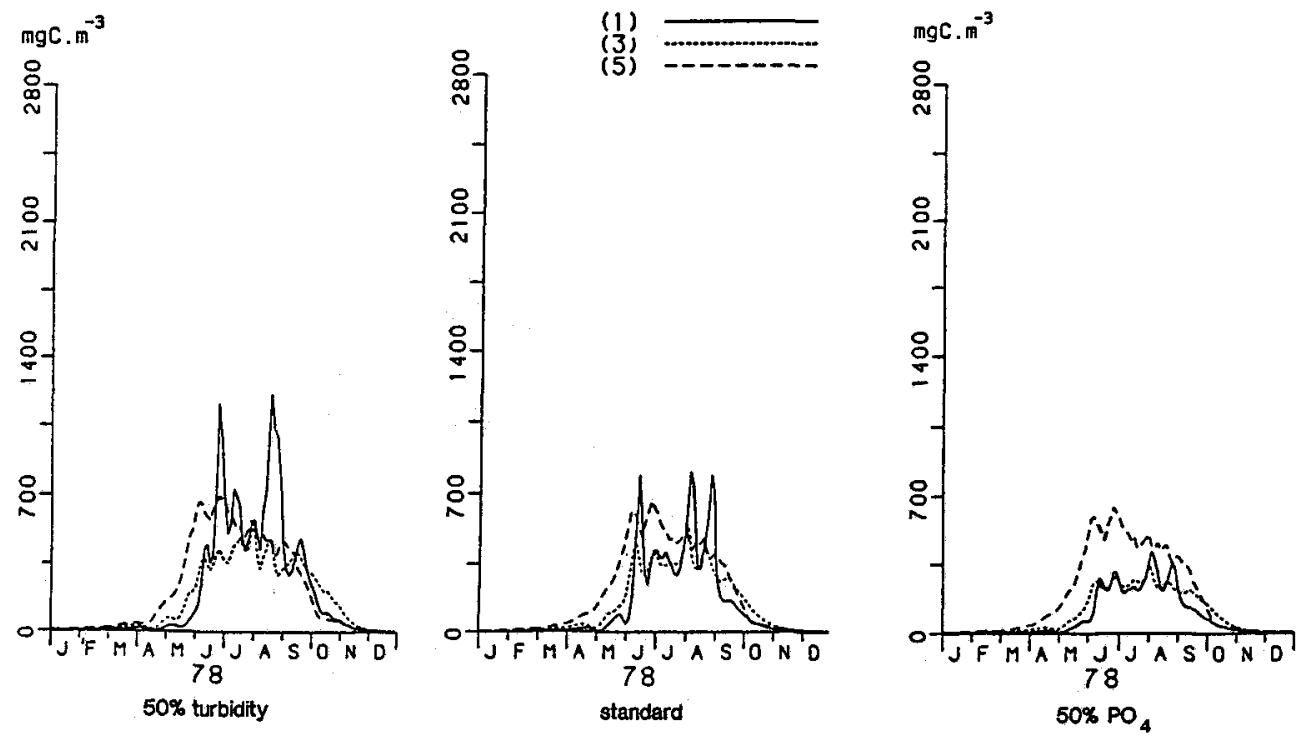

Fig. 3. Examples of annual variation in biomass of planktonic diatoms and planktonic flagellates in three compartments $(1,3$ and 5$)$, when the turbidity was halved $(50 \%)$ or the phosphate discharge was halved $(50 \%)$. For comparison the annual curves of the standard model are given 


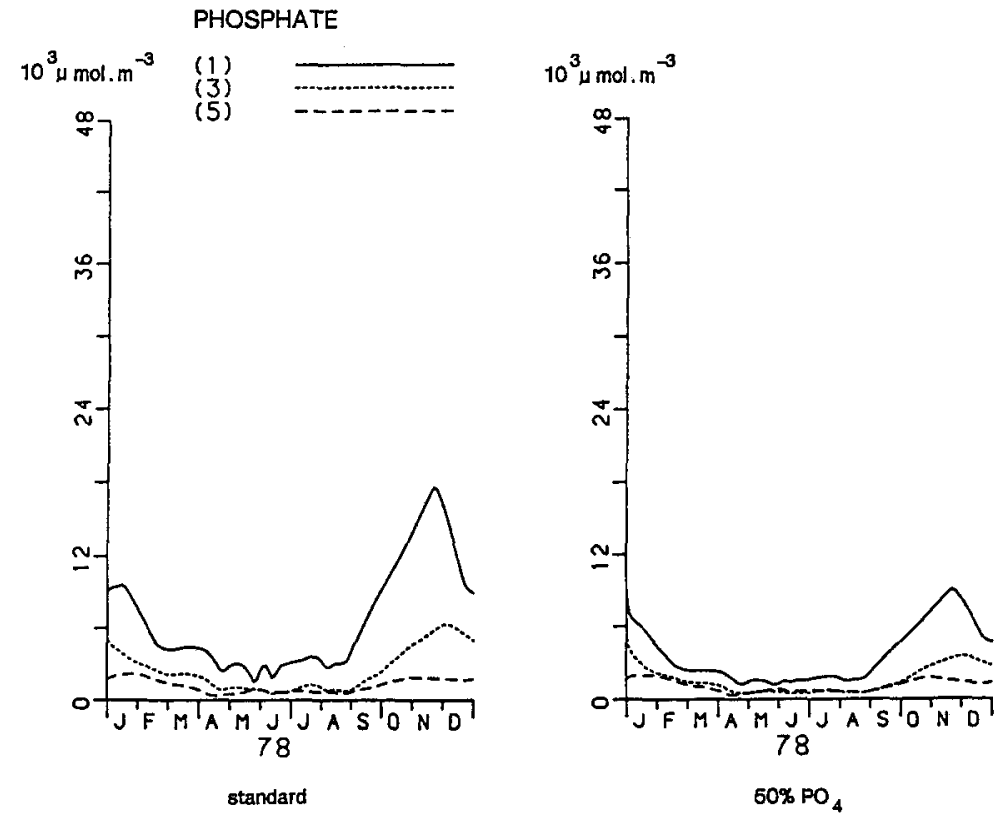

Fig. 4. Annual variation in phosphate concentrations in three compartments $(1,3$ and 5$)$ in the standard model and for the situation where the phosphate discharge from the rivers Ems and Westerwoldsche Aa was halved $(50 \%)$

turbidity (Fig. 6) is halved, the general trend in the intensity of the reaction is the same as for phosphate (DeGroodt $\&$ de Jonge, op. cit.). The strongest effects are again found in the upper reaches. This is because in that part of the estuary, where algal growth is usually lightlimited, these conditions have improved. The effect on the biota in the compartment near the sea is very low in this case too. The reason for this is that in the standard situation the light conditions in the water are already favourable for algal growth. However, when the turbidity is doubled the total stocks in the estuary drop. Although the decrease is strongest in the upper reaches (compartment 1), the stocks in the lower reaches near the sea boundary (compartment 5) also fall. It is clear that in the model bad light conditions lead to diminished primary production. Moreover, increased concentrations of suspended matter also negatively influence the energy balance of the suspension feeders (Essink \& Bos, 1985). These animals must (see above) remove large amounts of useless particles, which costs them a great deal of energy (Widdows et al., 1979). With respect to the turbidity, the same holds as for phosphate, namely that for monitoring programmes it seems justifiable to locate sampling areas in the upper and in the lowest reaches of the estuary.

The uncertainty in the model outcome should also be a point of discussion. This analysis of uncertainty was not incorporated in the study published by Baretta \& Ruardij (1988). However, the coefficient of variation in the irradiance attenuation coefficient (Colijn, 1982) can be estimated to be approx. $60 \%$ (mean value for the whole estuary over the period 1976 to 1980). It is not possible to give any value for the uncertainty in the model outcome on phosphate. For more detailed information on the applications given here the reader is referred to DeGroodt \& de Jonge (1989). 


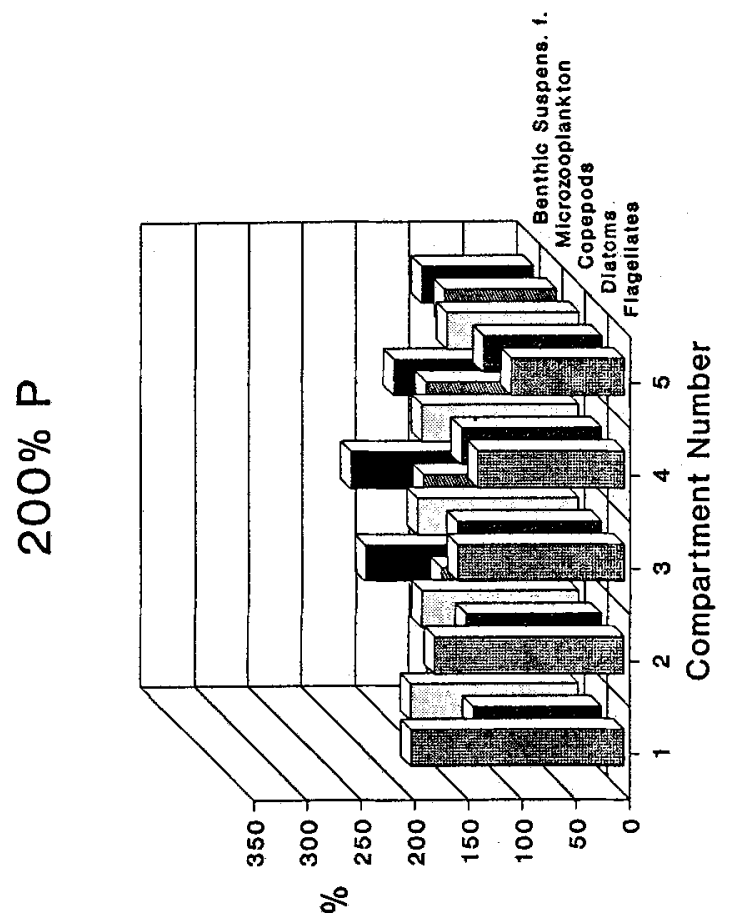

\pm
\pm
$\frac{5}{3}$ 落 葛 $\stackrel{\Xi}{\Xi}$

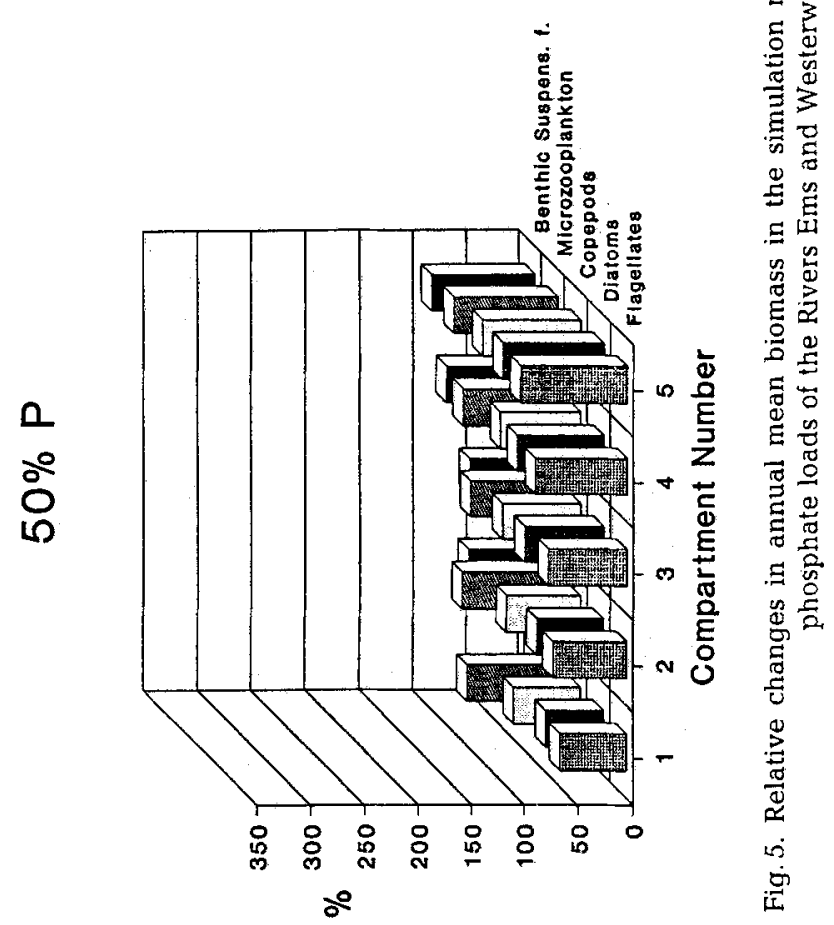




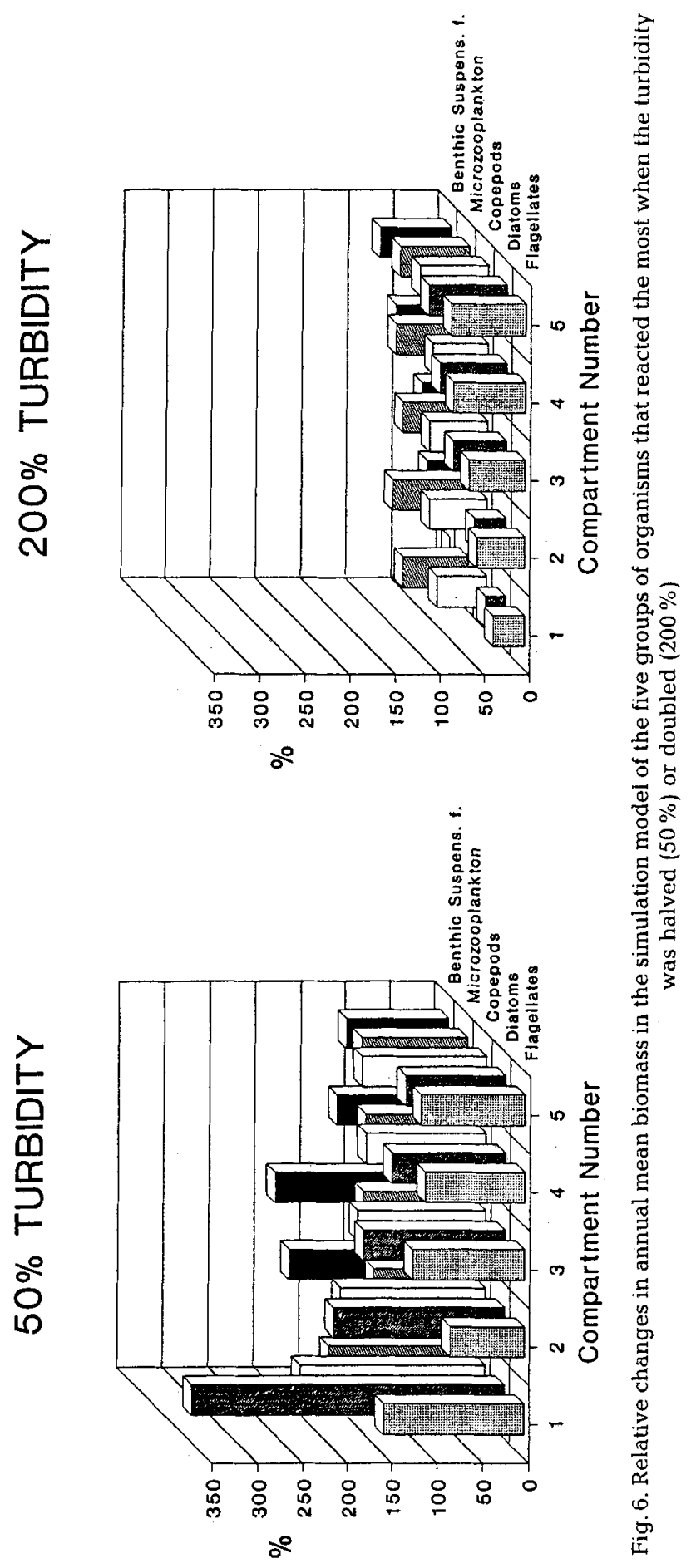


After the monitoring stations have been chosen, the sampling frequency and the number of sample replicates should also be considered. The necessity and consequences of this are extensively discussed by Cofino (1.989) and de Wolf (1989).

One factor that should be closely connected with monitoring seems to be the construction of simulation models (cf. Lindeboom et al., 1989) and the calibration and verification of such models. For verification, the models must be fed with data from specific years. So-called initial values are needed for the different variables, such as the standing stocks of the diatoms, of the algae that use no silicate (mainly flagellates) and of the different animal groups. But, it is equally important to have time series data for parameters at the boundaries of the area to be modelled. These boundary conditions include the salinity and nutrient concentrations at the sea boundary and, for the rivers, the fresh water discharge and nutrient loads. So, apart from monitoring the estuary itself, the boundaries of the area must be monitored to a certain extent. If a simulation model is available, a specific year can be simulated by combining the influx of compounds from the rivers, the time series of concentrations of compounds at sea and the starting values. Carrying out such a run and comparing some field data (seasonal variations in the biomass of phytoplanktonic diatoms and flagellates, suspension-feeders and depositfeeders) with the model results enables the model to be verified for that year. If the model describes the processes correctly, it should predict approximately the same standing stocks and the same fluxes as found for the sampling plots during the monitoring programme of that year.

Estuarine ecosystem models can also be used to optimize the frequency at which samples should be taken along estuarine boundaries (rivers and sea). In model runs, the time series data (e.g. on river discharge), which can be very variable for a rain-fed river, can be reduced to so few measurements that the predictions no longer agree with the measurements in nature. By comparing the results of runs made with different numbers of measurements, an optimal sampling programme for the boundary conditions can be identified. The model results can also be used to optimize the sampling frequency of biotic parameters e.g. that of fluctuating planktonic diatoms (Fig. 3). This means that optimal monitoring of planktonic diatoms can only be achieved by a programme with frequent sampling in spring, and less frequent sampling in winter.

Of course, there are restrictions to the use of models. Model simulation runs can only be carried out for parameters that are incorporated in the model. This means that models are not generally applicable (cf. Lindeboom et al., 1989). For certain problems we are forced to construct more specific models: for example, morphological models, two- and three-dimensional water transport models, sediment transport models, chemical and geochemical models. Another point of importance is that models will never be ready because our knowledge on the functioning of ecosystems continuously changes. Nevertheless, it is worth trying to build the "bridge between science and management" (Lindeboom et al., 1989) with models that make use of actual knowledge on the functioning of ecosystems. The advantage of modelling is that a model contains the actual knowledge in a very condensed but integrated form. Furthermore, both the model itself and the knowledge on specific years can be verified by programming the model with data from monitoring programmes. Another attractive point is that by using these models, new ideas on the functioning of estuarine ecosystems under changing conditions can be developed.

Today, monitoring alone is no longer sufficient for management strategies. Rough 
predictions, indicating deviations in the annual production values from the usual picture and/or shifts between different groups of organisms, are necessary to develop future management strategies. This does not mean that monitoring can be restricted solely to functional groups of organisms. Ecosystems also contain exotic or rare species or small populations of top predators, such as sea mammals, worth monitoring, although in terms of biomass, production or even predation these populations are often unimportant.

\section{CONCLUSIONS}

Merely monitoring the main physical, chemical or biological components is pointless when we are interested in the quality status of total ecosystems in terms of production and biomass of certain groups of organisms e.g. diatoms, flagellates, filter-feeders and deposit-feeders. Integral monitoring programmes are required for this.

Monitoring programmes carried out in dynamic estuarine ecosystems should be accompanied by:

(1) the use (if available) or the construction (if not available) of estuarine ecosystem models;

(2) the monitoring of the boundaries of the estuarine systems.

By doing this, new ideas on the functioning of estuarine ecosystems under changing environmental conditions can be developed and verified by field data. On the basis of this research, administrators can be advised on options for future management strategies. However, this does not mean that monitoring should be restricted only to the most important functional groups of organisms. It is also necessary to monitor rare species and small populations of top predators.

\section{LITERATURE CITED}

Baretta, J. \& Ruardij, P. (Eds), 1988. Tidal flat estuaries: Simulation and analysis of the Ems estuary. Springer, Berlin, $353 \mathrm{pp}$.

Cofino, W. P., 1989. Methodology of chemical monitoring in the marine environment. - Helgoländer Meeresunters. 43, 295-308.

Colijn, F., 1982. Light absorption in the waters of the Ems-Dollard estuary and its consequences for the growth of phytoplankton 'and microphytobenthos. - Neth. J. Sea Res. 15, 196-216.

DeGroodt, E. G. \& Jonge, V. N. de, 1989. A model study of the effects of changes in turbidity and influx of phosphate on the ecosystem of the Ems estuary. - Hydrobiologia (in press).

Dorrestein, R. \& Otto, L. 1960. On the mixing and flushing of the water in the Ems estuary. - Verh. K. ned. geol.-mijnb. Genoot. (Geol. Ser.) 19, 83-102.

Essink, K. \& Bos, A. H., 1985. Growth of three bivalve molluscs transplanted along the axis of the Ems estuary. - Neth. J. Sea Res. 19, 45-51.

Helder, W. \& Ruardij, P., 1982. A one dimensional mixing and flushing model of the Ems-Dollard estuary: calculation of time scales at different water discharges. - Neth. J. Sea Res. 15, 293-312.

Jonge, V. N. de, 1983. Relations between annual dredging activities, suspended matter concentrations, and the development of the tidal regime in the Ems estuary. - Can. J. Fish. aquat. Sci. 40 (Suppl. 1), 289-300.

Jonge, V. N, de, 1988. The abiotic environment. In: Tidal flat estuaries: Simulation and analysis of the Ems estuary. Ed. by J. Baretta \& P. Ruardij. Springer, Berlin, 14-27.

Jonge V. N. de, 1989. Response of the Dutch Wadden Sea ecosystem to phosphorus discharges from the river Rhine. - Hydrobiologia (in press).

Jonge, V. N. de \& Postma, H. 1974. Phosphorus compounds in the Dutch Wadden Sea. - Neth. J. Sea Res. 8, 139-153. 
Jonge, V.N. de \& Villerius, I. A., 1989. Possible role of carbonate dissolution in estuarine phosphate dynamics. - Limnol. Oceanogr. 34, 332-340.

Lindeboom, H. J., Raaphorst, W. van, Ridderinkhof, H. \& Veer, H. W. van der, 1989. Ecosystem model of the western Wadden Sea: a bridge between science and management? - Helgoländer Meeresunters. 43, 549-564.

Postma, H., 1960. Einige Bemerkungen über den Sinkstofftransport im Ems-Dollard-Gebiet. - Verh. K. ned. geol.-mijnb. Genoot. (Geol. Ser.) 19, 103-110.

Postma, H., 1967. Sediment transport and sedimentation in the estuarine environment. In: Estuaries. Ed. by G. H. Lauff. Am. Ass. Adv. Sci., Washington, 158-179.

Widdows, J., Fieth, P. \& Worrall, C. M., 1979. Relationships between seston, available food and feeding activity in the common mussel Mytilus edulis. - Mar. Biol. 50, 195-207.

Wolf, P. de, 1989. The price of patchiness. - Helgoländer Meeresunters. 43, 263-273. 